Global Cancer Statistics 2020: GLOBOCAN Estimates of Incidence and Mortality Worldwide for 36 Cancers in 185 Countries. CA Cancer J Clin, 71(3):209-249.

2. Glynne-Jones, R., Wyrwicz, L., Tiret, E., Brown, G., Rödel, C., Cervantes, A., \&Arnold, D (2017). Rectal cancer: ESMO Clinical Practice Guidelines for diagnosis, treatment and followup. Annals of Oncology, 28, iv22-iv40.

3. Trân Bằng Thống (2008). Nghiên cứu mối liên quan giữa khối u và mứcđộ xâm lấn mạc treo trong ung thư trực tràng, Luận văn thạc sỹ y học, Trường Đai hoc Y Hà Nội.

4. Vố Tấn Long, Nguyễn Minh Hải, Lâm Việt Trung và công sự (2011). Kết quả sớm của phẫu thuật nội soi cắt đoạn trực tràng nối máy so với mổ mở trong điều trị ung thư trực tràng. Tạp chí YHocTP.HồChíMinh,15(1), 119-123.

5. Nguyển Quang Thái, Nguyến Văn Hiếu, Trân
Nam Thắng (2008). Nghiên cứu kết quả phẫu thuâat nội soiđiêuu trị ung thư trực tràng tạibệnh viện K, Tapp Chí y học Tp. Hồ Chí Minh, 12(4).

6. Nguyễn Văn Hiếu (2002). Kết quả điều trị phẫu thuật của 205 bênh nhân UTTT tai bênh viên K từ 1994 - 2000. Hối nghị chuyên đề hậu môn - đại trực tràng, TP. Hồ Chí Minh, 191-208.

7. Trậ̂n Tuấn Thành (2014). Đánh giá kết quả phẫu thuâtt cắt đoan và nối máy trong ung thư trực tràng đoạn giữa, Luận văn thạc sĩ y học, Trường Đại học Y Hà Nội.

8. Nguyễn Minh Hải, Lâm Việt Trung (2003). Cắt nối máy trong ung thư trực tràng thấp. $Y$ học TP Hồ Chí Minh, 7(1), 155-16i.

9. Nguyễn Hoàng Bắc, Nguyễn Hữu Thịnh, (2008). Phấu thuật cắttoàn bô mạc treo trực tràng đánh giá chức năng sau nối thấp tânn-tân.Y Y Hoc TP. Hồ Chí Minh, 12(4).

\title{
ĐÁNH GIÁ SỰ THAY ĐỔI GIỌNG Ở BỆNH NHÂN VIÊM MŨI XOANG MAN TÍNH CÓ POLIP Độ III, IV TRƯớC VÀ SAU PHẪU THUÂ̂T NộI SOI MŨI XOANG CẮT POLIP MŨI
}

\section{TÓM TẮT}

Viêm mũi xoang man tính có polyp đô III - IV là một trong số những nguyên nhân ảnh hưởng tới kích thước hốc mũi, khe, hệ thống xoang, ảnh hưởng tới thông khí mũi, các cấu âm mũi và cộng hưởng . Để đánh giá mức đô ảnh hưởng tới chất lượng âm thanh và cấu âm ở những đổi tượng này, chúng tôi tiến hành nghiên cứu trên 30 bệnh nhân chẩn đoán viêm mũi xoang mạn tính, polip mũi độ III và IV, được phẫu thuật nội soi múi xoang, mở các xoang và cắt polip mũi tại Bệnh viện Tai Mũi Họng trung ương, được phân tích gionng trước và sau phẫu thuật bằng chương trình phân tích âm PRAAT. Kết quả: Tuổi: 45-65 chiếm tỷ lệ $56,7 \%$, Nam 70,0\%, nữ: 30,0\%. Lý do khám: ngạt tắc mũi: $73,3 \%$, ngủ ngáy $20,0 \%$,giảm hoăc mất ngửi $6,7 \%$. Triệu chứng cơ năng: ngạt tắc mũi $93,8 \%$, chảy mũi $63,3 \%$, ngủ ngáy $40,0 \%$,giảm hoặc mất ngửi $43,3 \%$, đau đâu $53,3 \%$, ho kéo dài $26,7 \%$, giảm thi lực 3,3\%. Triêu chứng thực thể: màu sắc cuốn mũi nhạt màu $100 \%$, quá phát cuốn dưới $40,0 \%$, thoái hoá cuốn giữa $66,7 \%$. Phân độ polip mũi: III (53,3\%), IV (46,7\%). Phim CT scan mũ̃i xoang tư thế coronal, axial và sargital: Bít tắc phức

${ }^{1}$ Bệnh viện Sản Nhi tỉnh Bắc Giang

${ }^{2}$ Trường Đại học Y Hà Nội

${ }^{3}$ Bênh viện Đại học Y Hà Nội

4Phòng khám Tai Mũi Họng 41/29 Vũ Ngọc Phan-Hà nội Chịu trách nhiệm chính: Phạm Thị Bích Đào

Email: phambichdao@hmu.edu.vn

Ngày nhận bài: 3.6.2021

Ngày phản biên khoa hoc: 28.7.2021

Ngày duyệt bài: 5.8.2021
Vũ Thị Dung1, Phạm Thị Bích Đào ${ }^{2,3}$, Trần Văn Tâm ${ }^{3}$, Mai Thị Mai Phương ${ }^{4}$

hợp lỗ ngách $100 \%$, thoái hoá cuốn 73,3\%, xoang hơi cuốn giữa $6,7 \%$,bít tắc khe khứu $60 \%$. Chất giọng: phụ âm mũi (m. n, ng, nh) trước phẫu thuật: Shimmer 9,671\%, Jitter 3,984\%, HNR 28,123 dB, F0 237Hz, F1 $1231 \mathrm{~Hz}, \mathrm{~F} 21007 \mathrm{~Hz}$. Sau phấu thuật: Shimmer $5,251 \%$, Jitter 1,984\%, HNR 22,003 dB, F0 $124 \mathrm{~Hz}$, F1 $892 \mathrm{~Hz}, \mathrm{~F} 2126 \mathrm{~Hz}$.

Tư khóa: viêm mũi xoang man - polip mũi đô III IV, chương trình PRAAT, chỉ số Śhimmer, Jitter,HNR, các formants.

\section{SUMMARY \\ EVALUATION OF VOICE: BEFORE AND AFTER ENDOSCOPIC SINUS SURGERY IN PATIENTS WITH CHRONIC RHINOSINUSITIS WITH NASAL POLYP GRADE III, IV}

Chronic Rhinosinusitis with nasal polyps accounted for $0.5-4 \%$ world population and $20 \%$ chronic rhinosinusitis patients. Chronic Rhinosinusitis with nasal polyps grade III, IV is one of the causes affecting the volume of the nasal cavity, nasal meatus, paranasal sinuses affect nasal ventilation, nasal sounds and resonances. To evaluate the impact on sound quality and articulation in these subjects, we conducted a study on 30 patients diagnosed with chronic rhinosinusitis with nasal polyps, grade III and IV, who underwent Endoscopic Sinus Surgery, open the sinuses and nasal polypectomy at the National Hospital of Otolaryngology, and analyzed their voice before and after surgery using the PRAAT sound analysis program. Results: Age: 1844 years old: $40.0 \%, 45-65$ years old: $56.7 \%$, over 65 years old: $3.3 \%$. Male: $70 \%$, female: $30 \%$. Reason for examination: Nasal congestion $73.3 \%$, snoring $20.0 \%$, reduction or loss of smell $6.7 \%$. Symptoms: Nasal 
congestion $93.8 \%$, nose discharge $63.3 \%$, snoring $40.0 \%$, reduction or loss of smell $43.3 \%$, headache $53.3 \%$, cough $26.7 \%$, reduction of vision $3.3 \%$. Physical symptoms: Nasal mucosa appear pale $100 \%$, inferior turbinate hypertrophy $40.0 \%$, middle turbinate degeneration $66.7 \%$. Nasal polyps grading: Grade III $53.3 \%$, grade IV $46.7 \%$. Paranasal sinus CT Scan with Coronal, Axial and Sargital scans: Ostiomeatus complexus obstruction $100 \%$, turbinate degeneration $73.3 \%$, olfactory cleft obstruction $60.0 \%$, concha bullosa $6.7 \%$. Voice assessment: Nasal consonants ( $\mathrm{m}$. $\mathrm{n}, \mathrm{ng}$, nh) before surgery: Shimmer $9.671 \%$, Jitter $3.984 \%$, HNR 28.123dB, F0 237Hz, F1 $1231 \mathrm{~Hz}, \mathrm{~F} 2$ $1007 \mathrm{~Hz}$. After surgery: Shimmer $5.251 \%$, Jitter $1.984 \%$, HNR 22.003dB, F0 124Hz, F1 892Hz, F2 $126 \mathrm{~Hz}$.

Keywords: chronic rhinosinusitis with nasal polyps grade III-IV ; PRATT program; Shimmer index; Jitter; HNR; formants.

\section{I. ĐẶT VẤN ĐỀ}

Viêm mũi xoang có polyp mũi chiếm 0,5 - 4\% dân số thế giới và ở khoảng $20 \%$ bệnh nhân bị viêm mũi xoang mạn tính ${ }^{1}$. Viêm mũi xoang mạn tính có polyp là một trong số những nguyển nhân làm thay đổi kích thước hốc mũi, khe, hệ thống xoang ${ }^{2}$. Những bệnh nhân viêm mũi xoang mạn tính có polyp mũi độ III - IV, làm hẹp từ $1 \frac{1}{2}$ đển $3 / 4$ độ rộng của hốc mũi, chính vì thế luồng không khí từ ngoài vào hốc mũi giảm, từ đó không khí xuống phổi giảm, ngược lại lượng hơi dự trữ từ phổi đi ra cũng giảm nên độ rung động của dây thanh yếu hơn, khoang cộng hưởng hẹp hơn từ độ rung, độ vang và phát âm của hầu hết các âm đều thay đổi ${ }^{3}$. Nhiêu nghiên cứu cho thấy những bệnh nhân viêm mũi xoang mạn tính polip mũi độ Iİ và IV luôn nói không rõ câu ${ }^{2,4,5}$. Ở Việt Nam, bệnh lý viêm mũi xoang mạn tính có polyp còn khá phổ biến ${ }^{6}$. Việc chỉ định điều trị và phẩu thuật mũi xoang chủ yếu còn nghiêng về tổn thương do bệnh tích ${ }^{7}$ mà chưa để ý tới chỉ định khi chức năng mũi xoang bị ảnh hưởng trong đó có chức năng phát âm và vai trò của mũi xoang với chất lượng giọng. Vì thế chúng tôi thực hiện đề tài: "Đánh giá sự thay đối giọng ở bệnh nhân viêm mũi xoang mạn tính có polyp mũi độ III, IV trước và sau phẫu thuật nội soi mũi xoang cắt polyp mũi "với hai mục tiêu: - Mô tả đặc điểm lâm sàng và chẩn đoán hình ảnh ở bệnh nhân viêm mũi xoang mạn tính có polyp mũi độ III, IV.

- Đánh giá sự thay đổi giọng ở bệnh nhân viêm mũi xoang mạn tính có polyp mũi độ III, IV trước và sau phấu thuật nội soi mũi xoang cắt polyp mũi.

\section{II. ĐỐI TƯỚNG VÀ PHƯƠ'NG PHÁP NGHIÊN CỨU}

2.1. Đối tượng nghiên cứu. 30 bệnh nhân chẩn đoán viêm mũ̃i xoang mạn tính, polyp mũi độ III, IV, được phâ̂u thuật nội soi mũi xoang tại
Bệnh viện Tai Mũi Họng TW từ tháng 8/2020 tới tháng 7/2021, được phân tích giọng trước và sau phẫu thuật bằng chương trình phân tích âm PRAAT

2.1.1. Tiêu chuẩn lựa chọn bệnh nhân

- Bệnh nhân là người trưởng thành ( $\geq 18$ tuổi)

- Được chẩn đoán viêm mũi xoang mạn tính, polyp mũ̃i độ III, IV có chỉ định phẫu thuật nội soi mũi xoang có cắt polyp mũi.

- Được ghi âm và đánh giá giọng trước và sau phẫu thuật bằng chương trình PRAAT, với các âm mũi mẫu: $m, n, n h$, ng

2.1.2. Tiêu chuẩn loại trừ. Hỏng mẫu câu ghi âm trong quá trình phân tích

\subsection{Phương pháp nghiên cứu}

2.2.1. Thiết kế nghiên cứu. Nghiên cứu mô tả từng ca.

2.2.2. Phương pháp chọn mẫu: Mẫu thuận tiện

2.4. Thu thập các thông số nghiên cứu

- Các thông số về đặc điểm chung của đối tượng nghiên cứu

- Các thông số về triệu chứng lâm sàng và cận lâm sàng của bệnh nhân trước phấu thuật nội soi mũi xoang

- Các thông số cuả phân tích giọng trước và sau phẫu thuật nội soi mũi xoang

\subsection{Các bước tiến hành}

Bước 1: Xây dựng bệnh án mẫu

Bước 2: Thu thập số liệu nghiên cứu

Bước 3: Phân tích số liệu, viết báo cáo kết quả và bàn luận kết quả thu được

Bước 4: Đưa ra kết luận và kiến nghị dựa trên kết quả thu được

2.6. Phân tích số liệu cụ thể: Các số liệu thu được qua bệnh án nghiên cứu, được xử lý trên phần mềm thống kê $Y$ học SPSS 16.0.

2.7. Đạo đức nghiên cứu: Nghiên cứu này tiến hành khi có sự đồng ý tham gia của người bệnh. Nghiên cứu không ảnh hưởng đến sức khỏe người bệnh, giúp người bệnh được tư vấn về bệnh và những thay đổi về giọng sau phẫu thuật. Đảm bảo tính trung thực, khách quan trong nghiên cứu.

\section{KẾT QUẢ NGHIÊN CỨU}

3.1. Đăc điểm chung của nhóm nghiên cứu

- Tuối: 19-44 tuổi: 40,0\%; 45-65 tuổi:

$56,7 \%$; trên 65 tuổi: 3,3\%

- Giới: Nam 70,0\%, nữ: 30,0\%.

- Lí do khám: ngạt tắc mũi: 73,3\%, ngủ ngáy $20,0 \%$, mất ngửi $6,7 \%$

- Triệu chứng cơ năng: ngạt tắc mũi 93,8\%, chảy mũi $63,3 \%$, ngủ ngáy $40,0 \%$, mất ngứi $43,3 \%$, đau đầu $53,3 \%$, ho kéo dài $26,7 \%$, giảm thị lực 3,3\% 


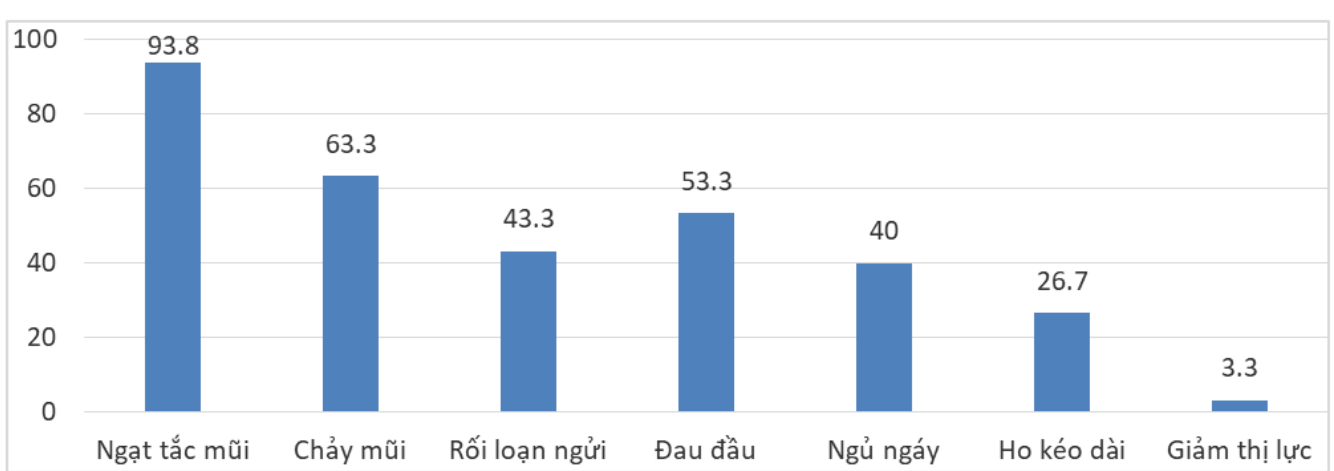

Biểu đồ1: Tỷ lệ triệu chứng cơ năng trong nghiên cứu

- Triêu chứng thực thể: màu sắc cuốn mũi nhạt màu $100 \%$, quá phát cuốn dưới $40,0 \%$, thoái hoá cuốn giữa $66,7 \%$

- Phân độ polip mũi: độ III (53,3\%), độ IV $(46,7 \%)$

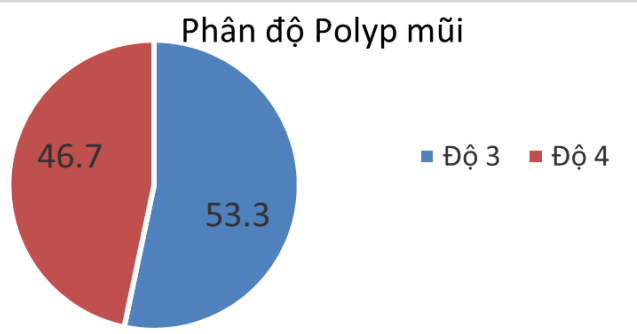

Biểu đồ 2: Tỷ lệ giữa Polyp mũi độ III và độ IV được phẫu thuật trong nghiên cứu

Nhận xét: Số bệnh nhân được chỉ định Phẫu thuật nội soi mũi xoang có cắt polyp mũi ở VMX mạn tính có polyp mũi độ III và độ IV lần lượt chiếm $53,3 \%$ và $46,7 \%$

- Phim CT scan mũi xoang tư thế Coronal, Axial có tái tạo bình diện Sagital: Bít tắc phức hợp lỗ ngách 100\%, thoái hoá cuốn 73,3\%, xoang hơi cuốn giữa $6,7 \%$, bít tắc khe khứu $60 \%$.

3.2. Phân tích giọng trước và sau phấu thuật nội soi mũi xoang có cắt polyp mũi:

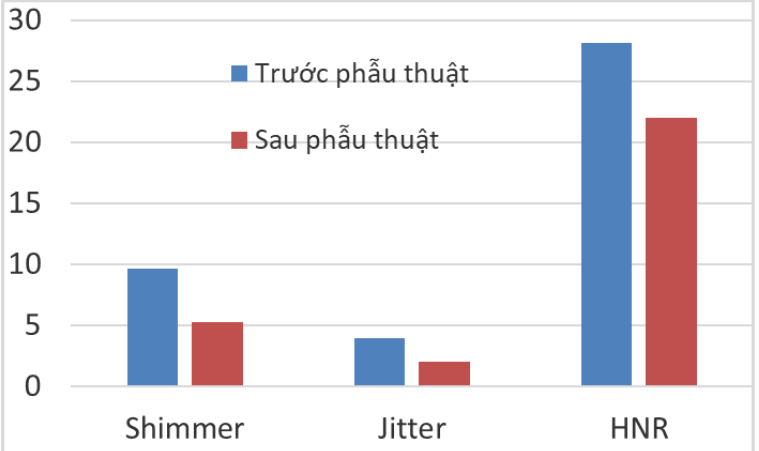

Biểu đồ 3.1. Các chỉ số Shimmer, Jitter, HNR của phụ âm mũi trước và sau phẫu thuật nội soi mũi xoang có cắt polyp mũi
Nhân xét: Phát âm phụ âm mũi trước khi phẫu thuật nội soi cắt polyp mũi: chỉ số Shimmer $9,671 \%$, Jitter 3,984\%, HNR 28,123dB. Sau phẫu thuật: Shimmer 5,251\%, Jitter 1,984\% , HNR 22,003dB. Các chỉ số này giảm đồng đều vế gần với trị số bình thường.

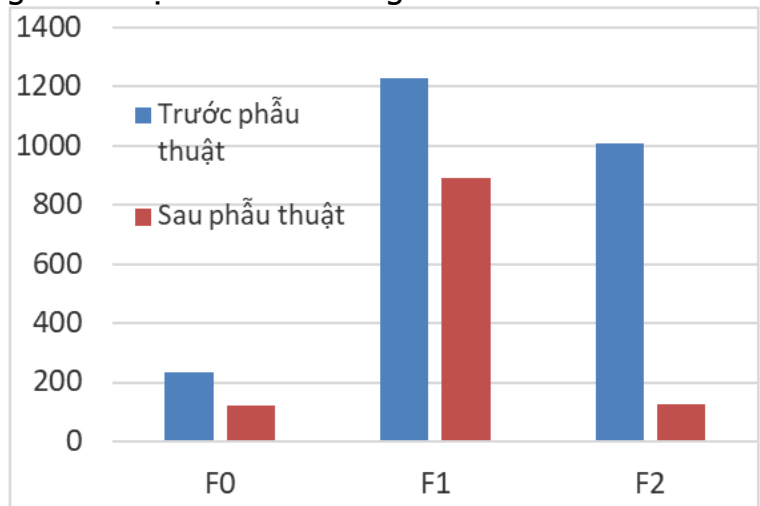

Biêu đồ 3.2: Biểu đồ FO và các formant của phụ âm mũi trước và sau phẫu thuật nội soi mũi xoang có cắt polyp mũi

Nhận xét: Tân số thanh cơ bản và các formant của phụ âm mũi trước khi phẫu thuật nội soi cắt polyp mũi: $F 0237 \mathrm{~Hz}, \mathrm{~F} 11231 \mathrm{~Hz}, \mathrm{~F} 2$ $1007 \mathrm{~Hz}$; sau phẫu thuật: F0 $124 \mathrm{~Hz}, \mathrm{~F} 1892 \mathrm{~Hz}$, F2 $126 \mathrm{~Hz}$. Các chỉ số này đều có xu hướng giảm đặc biệt là ở F2.

\section{BÀN LUẬN}

- Về độ tuổi và giới tính:Qua đánh giá 30 người bênh đã được phẫu thuât nội soi mũi xoang có cắt polyp mũi chúng tôi thấy $56,7 \%$ người bệnh ở độ tuổi từ 45-65 tuổi, tỷ lệ ở độ tuổi từ 19-44 tuổi và trên 65 tuổi lần lượt là 40\% và $3,3 \%$, tuổi trung bình là $48,8 \pm 13$. Kết quả này tương đối phù hợp với nghiên cứu của Lưu Anh Tuấn ${ }^{7}$, nhóm tuổi 46-60 chiếm tỷ lệ cao nhất là $34,9 \%$ với tuổi mắc bệnh trung bình là $42,5 \pm 13,5$, nghiên cứu của A.Acar và cộng sự với tuổi trung bình là $41 \pm 7$. Phẫu thuật nội soi 
mũi xoang có cắt polyp mũi có tỷ lệ khác biệt ở nam và nữ với tần xuất gặp: Nam $70,0 \%$, nữ: $30,0 \%$ trong nghiên cứu của chúng tôi. Tỷ lệ nam/nữ là 2,33 lần, tỷ lệ này cao hơn so với nghiên cứu của Lưu Anh Tuấn? là 1,4 lần nhưng phù hợp với nghiên cứu của $A$.Acar và cộng sự là 2,57 lần. Đặc điểm viêm mũi xoang man tính có polyp mũi thường gặp ở nam giới ở tuổi trung niên có lẽ ở đối tượng này có các yếu tố nguy cơ như hút thuốc lá, uống rượu bia, trào ngược họng thanh quản, làm việc tại các môi trường lao động ô nhiễm hay có nhiều khí độc.

\section{sàng:}

- Về lý do khám và các triệu chứng lâm

+ Về lí do khám: Đặc điểm, nghiên cứu của chúng tôi thấy bệnh nhẩn đến khám do: Ngạt tắc mũi: $73,3 \%$, ngủ ngáy $20,0 \%$, mất ngửi $6,7 \%$. Nghiên cứu của Lưu Anh Tuấn tỷ lệ bệnh nhân tới khám chủ yếu do ngạt tắc mũi với tỷ lệ lên tới $83,1 \%$.

+ Về triệu chứng cơ năng: Trong nghiên cứu của chúng ngạt tắc mũi $93,8 \%$, chảy mũi $63,3 \%$, ngủ ngáy $40,0 \%$, mất ngửi $43,3 \%$, đau đâu $53,3 \%$, ho kéo dài $26,7 \%$, giảm thị lực 3,3\%. Kết quả này tương đối phù hợp với kết quả của Lưu Anh Tuấn 7 ngạt tắc mũi $86,7 \%$, chảy mũi $80,7 \%$, ngủ ngáy $21,7 \%$, mất ngứi $34,7 \%$, đau nhức sọ mặt $42,2 \%$, ho kéo dài $3,6 \%$.

+ Về triệu chứng thực thể: màu sắc cuốn mũi nhạt màu $100 \%$, quá phát cuốn dưới $40,0 \%$, thoái hoá cuốn giữa $66,7 \%$. Trong nghiên cứu của Lưu Anh Tuấn? tỷ lệ thoái hoá cuốn giữa chiếm $79,6 \%$ còn quá phát cuốn dưới chỉ là $6 \%$, điều này có thể là do sự khác biệt trong lựa chọn đối tượng nghiên cứu.

+ Về phân độ Polyp mũi: độ III $(53,3 \%)$, độ IV $(46,7 \%)$ tỷ lệ polyp mũi độ III và độ IV không khác biêt nhiều. Kết quả này ở nghiên cứu của Lưu Tuẩn $A n h^{7}$ có sự khác biệt rõ, tỷ lệ polyp mũi độ III và độ IV lẩn lượt là $20,3 \%$ và $11,2 \%$, điều này có thể là do cỡ mẫu của chúng tôi chưa đủ lớn.

- Về đặc điểm CLVT: Trong nghiên cứu của chúng tôi: Bít tắc hợp lỗ ngách $100 \%$, thoái hoá cuốn $73,3 \%$, xoang hơi cuốn giữa $6,7 \%$, Bít tắc khe khứu $60 \%$. Kết quả này tương tự với nghiên cứu của Lưu Anh Tuấn tỷ lệ mờ phức hợp lỗ ngách $90,4 \%$, thoái hoá cuổn mờ khe khứu chiếm $54,2 \%$,

- Về chất giọng: Về chất giọng chúng tôi thu được: phát âm phụ âm mũi (m. $n, n g, n h)$ trước phẫu thuật: Shimmer $9,671 \%$, Jitter $3,984 \%$, HNR 28,123dB, F0 $237 \mathrm{~Hz}, \mathrm{~F} 11231 \mathrm{~Hz}$, F2 $1007 \mathrm{~Hz}$. Sau phẫu thuật: Shimmer 5,251\%,
Jitter 1,984\%, HNR 22,003dB, F0 $124 \mathrm{~Hz}, \mathrm{~F} 1$ $892 \mathrm{~Hz}, \mathrm{~F} 2126 \mathrm{~Hz}$. Như vậy ta thấy các chỉ số đều giảm sau phẫu thuật, các chỉ số giảm theo hướng gần với các giá trị bình thường của các chỉ số. Tương tự như nghiên cứu của A.Acar và cộng sự , ở nhóm những bệnh nhân có tắc nghẽn mứi một phần, các chỉ số sau phẫu thuật đều giảm Shimmer 3,7 , Jitter $0,7 \mathrm{~ms}$, NHR 0,13, riêng F0 tăng nhẹ, giá trị ở gian đoạn tắc nghẽn mũi hoàn toàn hoặc gần hoàn toàn lại tăng nhẹ ở cả 4 chỉ số này.

Tổng quát lại về các chỉ số trên các nghiên cứu: A.Acar và cộng sự trong nghiên cứu đã công bố thấy các chỉ số đánh giá mức độ nhiễu loạn của tần số,mức độ nhiễu loạn của biên độ, tỷ lệ chất thanh/tiếng ồn đều giảm, tuy nhiên tần số thanh cơ bản lại tăng ở các nhóm không có tắc nghẽn mũi và nhóm tắc nghẽn mũi 1 phần, ở nhóm có tắc nghẽn mũi hoàn toàn hoặc gần như hoàn toàn tất cả các chỉ số đều tăng sau phẫu thuật, điều này có thể là do cơ chế thích nghi gây ảnh hưởng tới giọng nói và cộng hưởng ở những người có tắc nghẽn mũi. Yे,-H. Kim và cộng sự đã nghiên cứu sự thay đổi về mũi, điểm GRBAS và thông số âm thanh trước khi phẫu thuật, một tháng và ba tháng sau phẫu thuật FESS có hoặc không phẫu thuật tạo hình vách ngăn. Họ nhận thấy có sự thay đổi đáng kể trong tất cả các phép đo $F 0$, Jitter, Shimmer và NHR được đo ở ba mốc thời gian, các chỉ số tăng dần sau phẫu thuật 1 tháng và giọng cải thiện rõ rệt sau phẫu thuật 3 tháng.

\section{KẾT LUẬN}

Sau phẫu thuật nội soi mũi xoang có cắt polyp mũi, giọng nói của người bệnh cải thiện rõ rệt.

\section{TÀI LIÊU THAM KHẢO}

1. Melfi RS. Communication Disorders: Overview, The Normal Communication Process, Voice Disorders (Dysphonia). Published online November 9, 2019. Accessed June 19, 2020.

2. Arslan $F$, Polat B, Durmaz A, Birkent H. Effects of Nasal Obstruction due to Nasal Polyposis on Nasal Resonance and Voice Perception. Folia Phoniatr Logop. 2016;68(3):141-143.

3. Dalston RM. Acoustic assessment of the nasal airway. Cleft Palate-Craniofacial J Off Publ Am Cleft Palate-Craniofacial Assoc. 1992;29(6):520-526.

4. Salturk $Z$, Uyar $Y$, Atar $Y$, et al. Subjective Evaluation of Vocal Quality in Nasal Polyposis. Haseki Tıp Bül. 2014;52:278-281.

5. Behrman A, Shikowitz MJ, Dailey S. The Effect of Upper Airway Surgery on Voice. Otolaryngol Neck Surg. 2002;127(1):36-42.

6. Soler ZM, Wittenberg E, Schlosser RJ, Mace JC, Smith TL. Health state utility values in patients undergoing endoscopic sinus surgery. The Laryngoscope. 2011;121(12):2672-2678. 
7. Lưu AT. Nghiên cứu đặc điểm lâm sàng, nội soi, cắt lớp vi tính và mô bệnh học của viêm mũi xoang man tính có polyp. Published online 2018.

8. Acar A, Cayonu M, Ozman M, Eryilmaz A. Changes in Acoustic Parameters of Voice After Endoscopic Sinus Surgery in Patients with Nasal
Polyposis. Indian J Otolaryngol Head Neck Surg Off Publ Assoc Otolaryngol India. 2014;66(4):381-385.

9. Kim YH, Lee SH, Park CW, Cho JH. Nasalance change after sinonasal surgery: analysis of voice after septoturbinoplasty and endoscopic sinus surgery. Am J Rhinol Allergy. 2013;27(1):67-70.

\section{KHẢO SÁT SỰ TUÂN THỦ THUỐC ĐIỀU TRI TĂNG HUYẾT ÁP Ở NGƯờI BỆNH TAI BIẾN MACH MÁU NÃO VÀ MộT SỐ YẾU TỐ LIÊN QUAN}

\section{TÓM TẮT}

Mục tiêu: Khảo sát mức độ tuân thủ thuốc điều trị tăng huyết áp (THA) ở bệnh nhân tai biến mạch máu não (TBMN) có THA đồng thời phân tích một số yếu tố liên quan. Đối tượng \& Phương pháp nghiên cứu: Nghiên cứu cắt ngang mô tả, thức hiên từ 9/2020 6/2021 trên202 người bệnh TBMN có THA điều trị tại khoa Thần kinh, Bênh viển Bach Mai. Dữ liêuu được thi thập qua bệnh án và bộ câu hỏi phỏng vấn được thiết kế sẵn. Đánh giá tuân thủ điều trị thuốc dựa vào thang điểm Morisky-8. Kết quả: Tuổi trung bình của nhóm nghiên cứu là $65,13 \pm 11,54$, trong đó nam giới chiếm $55 \%$. Sự hiểu biết của người bệnh về THA ở các mức độ như kém, trung bình vàcao lần lượt là $20,8 \%$, $47,0 \%$ và 32,3\%. Điểm Morisky-8 trung bình là $4,93 \pm 1,97$. Tỷ lệ tuân thủ thuốc điều trị THA ở mức đô kém, trung bình và cao lần lượt là $59,9 \%, 31,7 \%$ và $8,4 \%$. Giới tính, tuổi, việc tham gia bảo hiếm y tế, hút thuốc lá thường xuyên, thời gian bị THA và sự hiểu biết của người bênnh vế THA là các yếu tố liên quan độc lập với việc tuân thủ thuốc điều trị THA. Kết luận: Sự kém tuân thủ thuốc điều trị THA ở nhóm người bểnh nghiên cứuchiếm tỷ lệ cao $(59,9 \%)$. Các yếu tố liển quan độc lập với sự tuân thủ điều trị THA được gh nhân gồm: nhóm tuổi trên 50, nữ giới, tham gia bảo hiểm y tế, không hút thuốc lá, thời gian mắc THA trên 5 năm và sư hiếu biết đầy đủ của người bênh về THA.

Tư khóa: Tuân thủ thuốc, Tai biến mạch máu não, Tăng huyết áp, Thang điểm Morisky-8

\section{SUMMARY}

INVESTIGATION OF MEDICATION

ADHERENCE TO ANTIHYPERTESIVE DRUGS

AND SOME RELATED FACTORS AMONG

HYPERTENSIVE STROKE PATIENTS

Objective: To investigate the medication adherence (MA)to antihypertensive drugs and to analyze some related factorsamong hypertensive stroke patients. Patients and methods: A cross-

\section{*Bệnh viện đa khoa tỉnh Ninh Binh}

**Trường Đai hoc Y Hà Nôi

Chiu trách nhiệm chính: Phùng Văn Ngọc

Email: bsphungngoc@gmail.com

Ngày nhận bài: 3.6.2021

Ngày phản biên khoa học: 26.7.2021

Ngày duyệt bài: 4.8.2021

\section{Phùng Văn Ngọc*, Nguyễn Trọng Hưng**}

sectional study involving 220 hypertensive stroke patients was conducted from September 2020 to June 2021 in Neurology Department of Bach Mai hospital. Data were collected through medical records and designed questionnaire. Assessment of MA to antihypertensive drugs was based on Morisky Medication Adherence Scale-8. Result: The average age of patients was $65.13 \pm 11.54$ with male $55 \%$. $20.8 \%, 47.0 \%$ and $32.3 \%$ of patients had poor, moderate and adequate knowledge of hypertension, respectively. The average Morisky-8 score was 4.93 \pm 1.97 . The percentage of MA to antihypertensive drugs amonghypertensive stroke patients was poor, moderate, and high at $59.9 \%, 31.7 \%$ and $8.4 \%$, respectively. Gender, age, health insurance, current smoking, duration of hypertension, and patient's knowledge of hypertension were independently associated with MA among hypertensive stroke patiens. Conclusion: The poor MA to antihypertensive drugs among hypertensive stroke patientsaccounted for a high rate (59.9\%). Related factors associated independentlywith MA in these patientsinclude: age group over 50, female, health insurance, non-smoker, duration of hypertension over 5 years, and good understanding of hypertension.

Keyword: Medication adherence, Stroke, Hypertension, MoriskyMedication Adherence Scale-8

\section{I. ĐĂT VẤN ĐỀ}

Tai biến mạch máu não (TBMN) hiện đang là vấn đề thời sự với nền y học thế giới, là một trong những nguyên nhân gây tử vong và tàn tật hàng đâu. Có nhiều yếu tố nguy cơ của tai biến mạch máu não, trong đó tăng huyết áp (THA) là một yếu tố nguy cơ thường gặp nhất. Nhiêu nghiên cứu đã chỉ ra rằng kiểm soát tốt huyết áp bằng thuốc sẽ làm giảm tỷ lệ mắc TBMN ở cả hai giới và mọi lứa tuổi [1]. Kiểm soát huyết áp bao gồm các vấn đề dùng thuốc và không dùng thuốc, trong đó việc dùng thuốc đóng vai trò quan trọng. Tỷ lệ kiểm soát huyết áp trong các nghiên cứu trên thế giới và tại Việt Nam còn thấp. Các nghiên cứu về tuân thủ thuốc điêuu trị THA trước nay ở Việt Nam mới chỉ tập trung vào THA tại cộng đồng, chưa có nhiều nghiên cứu 